\title{
The involvement of Eag1 potassium channels and miR-34a in rotenone-induced death of dopaminergic SH-SY5Y cells
}

\author{
CAMILA HILLESHEIM HORST, RICARDO TITZE-DE-ALMEIDA and SIMONEIDE SOUZA TITZE-DE-ALMEIDA
}

\author{
Technology for Gene Therapy Laboratory, Central Institute of Sciences, \\ Faculty of Agronomy and Veterinary Medicine, University of Brasília, Brasília 70910-900, Brazil
}

Received December 28, 2015; Accepted November 25, 2016

DOI: $10.3892 / \mathrm{mmr} .2017 .6191$

\begin{abstract}
The loss of dopaminergic neurons and the resultant motor impairment are hallmarks of Parkinson's disease. The SH-SY5Y cell line is a model of dopaminergic neurons, and allows for the study of dopaminergic neuronal injury. Previous studies have revealed changes in Ether à go-go 1 (Eag1) potassium channel expression during p53-induced SH-SY5Y apoptosis, and the regulatory involvement of microRNA-34a (miR-34a) was demonstrated. In the present study, the involvement of Eag1 and miR-34a in rotenone-induced SH-SY5Y cell injury was investigated. Rotenone is a neurotoxin, which is often used to generate models of Parkinson's disease, since it causes the death of nigrostriatal neurons by inducing intracellular aggregation of alpha synuclein and ubiquitin. In the present study, rotenone resulted in a dose-dependent decrease in cell viability, as revealed by 3-(4,5-dimethylthiazol-2-yl)-2,5-diphenyltetrazolium bromide (MTT) and trypan blue cell counting assays. In addition, Eag1 was demonstrated to be constitutively expressed by SH-SY5Y cells, and involved in cell viability. Suppression of Eag1 with astemizole resulted in a dose-dependent decrease in cell viability, as revealed by MTT assay. Astemizole also enhanced the severity of rotenone-induced injury in SH-SY5Y cells. RNA interference against Eag1, using synthetic small interfering RNAs (siRNAs), corroborated this finding, as siRNAs potentiated rotenone-induced injury. Eag1-targeted siRNAs (kv10.1-3 or EAG1hum_287) resulted in a statistically significant $16.4-23.5 \%$ increase in vulnerability to rotenone. An increased number of apoptotic nuclei were observed in cells transfected with EAG1hum_287. Notably, this siRNA intensified rotenone-induced apoptosis, as revealed by an increase
\end{abstract}

Correspondence to: Dr Simoneide Souza Titze-de-Almeida, Technology for Gene Therapy Laboratory, Central Institute of Sciences, Faculty of Agronomy and Veterinary Medicine, University of Brasília, 128 Darcy Ribeiro Academic Campus, Brasília 70910-900, Brazil

E-mail: simoneide.silva@gmail.com

Key words: Eag1, neurodegenerative diseases, rotenone, RNA interference in caspase 3/7 activity. Conversely, a miR-34a inhibitor was demonstrated to exert neuroprotective effects. The viability of cells exposed to rotenone for 24 or $48 \mathrm{~h}$ and treated with miR-34a inhibitor was restored by $8.4-8.8 \%$. In conclusion, Eag1 potassium channels and miR-34a are involved in the response to rotenone-induced injury in SH-SY5Y cells. The neuroprotective effect of mir-34a inhibitors merits further investigations in animal models of Parkinson's disease.

\section{Introduction}

Parkinson's disease is the second most prevalent neurodegenerative disorder (1). The etiology of Parkinson's disease is complex, and comprises genetic and environmental factors. Agricultural pesticides are well-established causes of parkinsonism (2). Among them is the toxin rotenone; a lipophilic molecule that easily crosses the blood-brain barrier. Rotenone mimics several features observed in Parkinson's disease, including dopaminergic neuronal death, oxidative stress, behavioral changes and inflammation $(3,4)$. In addition, rotenone results in an intracellular aggregation of synuclein and ubiquitin that resembles Lewy bodies, a classic hallmark of Parkinson's disease $(5,6)$. The rotenone model has previously been used in in vitro and in vivo studies to investigate the neurobiology of Parkinson's disease (3).

The loss of nigrostriatal dopaminergic neurons, followed by a decrease in striatal dopamine content, is a neurochemical change observed in patients with Parkinson's disease (7). In the present study, the SH-SY5Y neuronal cell line was used as an in vitro model of dopaminergic neurons. It mimics several features of dopaminergic neuronal death in a well-controlled environment of cultured cells, remaining a valuable cell line for studies relating to neurotoxicity (8). A previous study using SH-SY5Y cells revealed that Ether à go-go 1 (Eag1) potassium channels are the final effectors of a signaling cascade triggered by $\mathrm{p} 53$. Activation of $\mathrm{p} 53$, which results in cell cycle arrest or apoptosis, reduced the expression of Eag1 channel (9). Previous studies using the 6-hydroxydopamine (6-OHDA) model of Parkinson's disease revealed that 6-OHDA results in the p53-dependent death of dopaminergic cells, which was correlated with a decrease in Eag1 immunoreactivity $(10,11)$.

Eag1 channels are associated with the physiology of excitable cells, and are involved in cell cycle progression and growth (12-14). However, the lack of specific Eag1 channel 
blockers has limited studies regarding the involvement of Eag1 in the health-disease processes. RNA interference (RNAi) techniques circumvent this limitation, as these allow the silencing of potentially any target gene. This method has been successfully used in numerous previous studies relating to Parkinson's disease pathology and experimental therapeutics, as reviewed by Manfredsson et al (15). Eag1 RNAi decreases gene expression and channel activity, affecting the viability of various cancer cell types (16). The present study used a small interfering RNA (siRNA) molecule that targets the same mRNA sequence described by a previous study, named Kv10.1-3 (16). In addition, an Eag1-targeted siRNA with a higher silencing effect on Eag1, EAG1hum_287, was examined (17).

MicroRNAs (miRNAs) are noncoding RNAs implicated in the pathogenesis of Parkinson's disease $(18,19)$. The present study focused on miRNA-34a (miR-34a), which is involved in SH-SY5Y apoptosis as part of a biochemical cascade that involves p53, E2F transcription factor 1 (E2F1) and Eag1 (9). Previous studies have revealed that inhibition of miR-34a may protect hippocampal cells from lithium-pilocarpine and kainic acid-induced injury $(20,21)$. The present study aimed to evaluate the involvement of miR-34a and Eag1 potassium channels in the rotenone-induced injury of dopaminergic SH-SY5Y cells.

\section{Materials and methods}

Cell culture. Human neuroblastoma SH-SY5Y cells (CRL-2266 ${ }^{\circledR}$; American Type Culture Collection, Manassas, VA, USA) were grown in Dulbecco's modified Eagle's medium (DMEM)/F12 medium (Gibco; Thermo Fisher Scientific, Inc., Waltham, MA, USA) containing 10\% heat-inactivated fetal bovine serum (Gibco; Thermo Fisher Scientific, Inc.), 1\% Glutamax (Gibco; Thermo Fisher Scientific, Inc.), $100 \mu \mathrm{g} / \mathrm{ml}$ streptomycin, $100 \mathrm{U} / \mathrm{ml}$ penicillin $\mathrm{G}$ and $250 \mathrm{ng} / \mathrm{ml}$ amphotericin B (Sigma-Aldrich; Merck Millipore; Darmstadt, Germany), at $37^{\circ} \mathrm{C}$ in a humidified atmosphere containing $5 \%$ $\mathrm{CO}_{2}$ and $95 \%$ air.

siRNA and miRNA inhibitors. The present study used the previously described siRNAs Kv10.1-3 and EAG1hum_287 (18.75 nM; Qiagen GmbH, Hilden, Germany) (17). The commercial scramble AllStars negative control siRNA was used as a negative control (Qiagen, Inc., Valencia, CA, USA).

A synthetic miRNA inhibitor, synthesized as locked nucleic acids (LNA) in phosphorothionate backbones and targeting the human miR-34a (hsa-miR-34a-5p), with the sequence 5'-AGCTAAGACACTGCC-3' (30 nM; miRCURY LNA $^{\mathrm{TM}}$; Exiqon A/S, Vedbaek, Denmark) was also used. A miRNA inhibitor negative control was synthesized with the same structural modifications, with the following sequence: 5'-ACGTCTATACGCCCA-3' (Custom miRCURY LNA ${ }^{\mathrm{TM}}$ Power Inhibitor, Exiqon A/S).

Cell transfection. The siRNAs (Kv10.1-3 and EAG1hum_287) and scramble negative controls were transfected into the SH-SY5Y cells using Lipofectamine ${ }^{\circledR} 2000$ transfection reagent, according to the manufacturer's protocol (Invitrogen; Thermo Fisher Scientific, Inc.). The miR-34a inhibitor and the scramble negative control were transfected using Interferin (Polyplus-transfection SA, Illkirch-Graffenstaden, France). The oligonucleotides were diluted in Opti-Mem I reduced serum media (Invitrogen; Thermo Fisher Scientific, Inc.; Kv10.1-3 and EAG1hum_287) or serum-free DMEM (miR-34a inhibitor). Transfection reagents were subsequently added, mixed by vortexing, and incubated for $10 \mathrm{~min}$ at room temperature. Rotenone-injured cell groups and non-injured controls were incubated with the transfection reagents for $24 \mathrm{~h}$ at $37^{\circ} \mathrm{C}$. The used experimental groups are detailed in each respective figure legend, as well as experimental conditions and time-points of transfection.

Quantification of Eagl $m R N A$ content by reverse transcription-quantitative polymerase chain reaction $(R T-q P C R)$. To determine Eag1 mRNA cell content, total RNA was first extracted with a commercial kit (RNeasy Plus Mini kit; Qiagen $\mathrm{GmbH}$ ). RNA integrity was analyzed by $1 \%$ agarose gel electrophoresis stained with ethidium bromide (Invitrogen; Thermo Fisher Scientific, Inc.). A DNA Ladder (1 kb) was used as a molecular weight marker (Thermo Fisher Scientific, Inc.). The absence of DNA contamination was confirmed by qPCR using negative RT controls. Total RNA was quantified by fluorometry (Qubit ${ }^{\circledR} 2.0$ firmware 3.11; Thermo Fisher Scientific, Inc.). cDNA was synthesized from $500 \mathrm{ng}$ total RNA using random primers, according to the manufacturer's protocol (SuperScript First-Strand Synthesis System for RT-PCR; Invitrogen; Thermo Fisher Scientific, Inc.). RT-qPCR reactions were performed using a QuantStudio 12K Flex system (Applied Biosystems; Thermo Fisher Scientific, Inc.). The primer sequences used for Eag1 amplification were as follows: Forward, 5'-TCTGTCCTG TTTGCCATATGATGT-3' and reverse, 5'-CGGAGCAGC CGGACAA-3' (16). For the reference gene, the following poly (A) polymerase alpha primer sequences were used: Forward, 5'-GCTACGAAGACCAGTCCATTG-3' and reverse, 5'-TGT TGGTCACAGATGCTGCT-3' (22). Amplification products were detected via intercalation of the fluorescent dye SYBR Green. The reaction mix contained 5.0 $\mu$ 1 Fast SYBR Green Master Mix (Applied Biosystems; Thermo Fisher Scientific, Inc.), $2.0 \mu \mathrm{l}$ cDNA (dilution, 1:10), $0.4 \mu 1$ sense and $0.4 \mu 1$ antisense primers $(10 \mathrm{pmol} / \mu \mathrm{l})$, and milli-Q pure water up to $10.0 \mu \mathrm{l}$. The PCR program included initial denaturation at $95^{\circ} \mathrm{C}$ for $5 \mathrm{~min}$, followed by 40 cycles of amplification $\left(95^{\circ} \mathrm{C}\right.$ for $1 \mathrm{~min}, 60^{\circ} \mathrm{C}$ for $1 \mathrm{~min}$ ). Each run was performed in triplicate, and the assay included negative RT (non-template) controls. $\Delta \Delta \mathrm{Cq}\left(2^{-\Delta \Delta \mathrm{Cq}}\right)$ relative quantification was used to quantify the effects of Eag1-targeted siRNAs on Eag1 mRNA content (23). Melting curves were determined during all standardization of qPCR methodologies, according to Ririe et al (24).

Quantification of miR-34a content in SH-SY5Y cells by $R T-q P C R$. Total miRNA was extracted using a commercial kit (mirVana $^{\mathrm{TM}}$ miRNA Isolation kit; Ambion ${ }^{\mathrm{TM}}$; Thermo Fisher Scientific, Inc.), and quantified by fluorometry (Qubit ${ }^{\circledR} 2.0$ firmware 3.11; Thermo Fisher Scientific, Inc.). cDNA was synthesized using TaqMan MicroRNA Reverse Transcription kit (Applied Biosystems; Thermo Fisher Scientific, Inc.), from $2 \mathrm{ng} / \mu \mathrm{l}$ of miRNA. This assay entailed a two-step RT-qPCR for each miRNA. The process is performed using a 
stem-loop primer that binds to specific miRNA to transcribe it onto a longer cDNA that is amenable for amplification using a commercial kit (TaqMan ${ }^{\circledR}$ Fast Advanced Master Mix kit; Applied Biosystems; Thermo Fisher Scientific, Inc.). RT-qPCR reactions for miR-34a were performed using a QuantStudio 12K Flex system (Applied Biosystems; Thermo Fisher Scientific, Inc.). The reaction mix contained $10.0 \mu \mathrm{l}$ TaqMan ${ }^{\circledR}$ Fast Advanced Master Mix (Applied Biosystems; Thermo Fisher Scientific, Inc.), $2.0 \mu \mathrm{l}$ cDNA, $1.0 \mu \mathrm{l}$ primers for miR-34a (hsa-miR-34a, 000426) or the reference gene RNU6B (RNU6B, 001093; Thermo Fisher Scientific, Inc.), and milli-Q pure water up to $20.0 \mu \mathrm{l}$. The qPCR program included two initial cycles $\left(50^{\circ} \mathrm{C}\right.$ for $2 \mathrm{~min}, 95^{\circ} \mathrm{C}$ for $\left.20 \mathrm{sec}\right)$, followed by 40 cycles of amplification $\left(95^{\circ} \mathrm{C}\right.$ for $1 \mathrm{~min}, 60^{\circ} \mathrm{C}$ for $\left.1 \mathrm{~min}\right)$. Each run was performed in triplicate, and the assay included negative RT (non-template) controls. $\Delta \Delta \mathrm{Cq}\left(2^{-\Delta \Delta \mathrm{Cq}}\right)$ relative quantification was used to quantify the effects of miR-34a inhibitors on miR-34a cell content (23).

Immunocytochemistry. SH-SY5Y cells ( $10^{5}$ cells/well) were incubated for $24 \mathrm{~h}$ on coverslips in 24-well plates for immunocytochemical detection of Eag1. Cells were fixed with $4 \%$ paraformaldehyde for $5 \mathrm{~min}$ and were then incubated for $1 \mathrm{~h}$ in blocking solution (5\% horse serum; Gibco; Thermo Fisher Scientific, Inc.) and 0.3\% Triton X-100 (Sigma-Aldrich; Merck Millipore) in phosphate-buffered saline (PBS; Sigma-Aldrich; Merck Millipore) at room temperature. Subsequently, the primary Eag1 antibody (mAb 62 mouse 1:1,000; kindly provided by Professor Walter Stühmer, MPI, Göttingen, Germany) was added to the cells, and incubated overnight at $4^{\circ} \mathrm{C}$ under agitation. The cells were washed three times at room temperature $(5 \mathrm{~min} /$ wash under agitation). The secondary antibody (Alexa-fluor 488 anti-mouse 1:2,000; cat. no. A-11001; Molecular Probes; Thermo Fisher Scientific, Inc.) was then applied and the cells incubated for $1 \mathrm{~h}$ at room temperature (in a dark box under agitation). SH-SY5Y cell nuclei were stained with Hoechst 33342 (Sigma-Aldrich; Merck Millipore) and washed three times in PBS at room temperature ( $5 \mathrm{~min} /$ wash under agitation). The coverslips were mounted in Entellan ${ }^{\circledR}$ (Merck Millipore) and analyzed using a fluorescence microscope (Leica DM2000; Leica Microsystems $\mathrm{GmbH}$, Wetzlar, Germany). Cells treated without the primary antibody were used as a negative control. Experimental conditions and time-points of immunocytochemical detection of Eag1 are described in the figure legends.

Determination of cell viability by MTT assay. Quantification of cell viability was determined using a colorimetric assay with MTT (Invitrogen; Thermo Fisher Scientific, Inc.), which exhibits the mitochondrial activity of living cells. Cells were seeded in 96 -well plates $\left(5 \times 10^{4}\right.$ cells/well $)$ and incubated for $24 \mathrm{~h}$ in a humidified atmosphere containing $5 \%$ $\mathrm{CO}_{2}$ and $95 \%$ air at $37^{\circ} \mathrm{C}$. Subsequently, cells were exposed to astemizole $(2.5,5.0$ or $7.5 \mu \mathrm{M})$ or rotenone $(2.5,10.0$ or $20.0 \mu \mathrm{M}$ ) for an additional period of $24 \mathrm{~h}$. Cell viability was then determined by MTT. In siRNA-transfected groups, cells were exposed to rotenone for $24 \mathrm{~h}$ and transfected with EAG1hum_287 (18.75 nM) or the scramble control (18.75 nM) mixed with Lipofectamine. Cell viability was evaluated
$24 \mathrm{~h}$ post-transfection. For the MTT assay, each well was treated with $50 \mu 1$ MTT-labeling reagent $(0.5 \mathrm{mg} / \mathrm{ml})$, and the plate was incubated in a humidified atmosphere containing $5 \% \mathrm{CO}_{2}$ and $95 \%$ air at $37^{\circ} \mathrm{C}$ for an additional $3 \mathrm{~h}$. The formazan crystals were dissolved with dimethyl sulfoxide (Sigma-Aldrich; Merck Millipore), and MTT reduction was detected at $595 \mathrm{~nm}$ using a SpectraMax M2 (SpectraMax M2 Microplate Reader; Molecular Devices, LLC, Sunnyvale, CA, USA). Cell viability was measured as a percentage of the value observed in untreated control cells. The treatments were performed in triplicate and the experiments repeated three times. Experimental conditions and time points of the MTT assay are stated in the figure legends. MTT assay was also used to evaluate cell viability post-transfection with the miR-34a inhibitor. Cell transfection was executed at 2 or $24 \mathrm{~h}$ following rotenone exposure and cell viability was measured at 24 or $48 \mathrm{~h}$.

Counting of viable cells using the trypan blue exclusion method. SH-SY5Y cells were seeded in a 6-well plate $\left(5 \times 10^{5}\right.$ cells/well) and incubated in a humidified atmosphere containing $5 \% \mathrm{CO}_{2}$ and $95 \%$ air at $37^{\circ} \mathrm{C}$ overnight. Cells were exposed to rotenone $(2.5$ or $10 \mu \mathrm{M})$ for $24 \mathrm{~h}$ for cell viability evaluation. Cell suspension $(50 \mu \mathrm{l})$ was collected and mixed with an equal volume of $0.4 \%$ trypan blue (Sigma-Aldrich; Merck Millipore). Viable cells were counted as clear cells and dead cells as blue cells under light microscopy, in a Neubauer chamber. The number of live cells per $\mathrm{ml}$ was calculated using the following formula: Viable cells $(\%)=($ live cell count/total cell count) x100. The number of viable cells at each concentration and time point was determined in triplicate.

Nuclear staining with Hoechst 33342. SH-SY5Y cells $\left(10^{5}\right.$ cells/well) were grown on coverslips in 24 -well plates. Following $24 \mathrm{~h}$ of rotenone exposure, cell transfection with siRNA EAG1hum_287 (18.75 nM) or the scramble control (18.75 nM) was performed for an additional $24 \mathrm{~h}$. Hoechst 33342 assays were then used to detect apoptotic cells. SH-SY5Y cells were fixed with $4 \%$ paraformaldehyde for $10 \mathrm{~min}$. Cells were stained with Hoechst $33342(10 \mu \mathrm{g} / \mathrm{ml} /$ well $)$ in the dark at room temperature for $5 \mathrm{~min}$. Finally, the coverslips were washed three times with PBS, air-dried, mounted onto glass slides and analyzed under a fluorescence microscope. Fragmentation, nuclear condensation and bright staining of apoptotic cells were determined by visually inspecting the intensified local staining in the nucleus, in comparison to diffused staining of DNA in normal cells.

Caspase 3/7 apoptosis assays. To measure caspase 3/7 activity, SH-SY5Y cells $\left(5 \times 10^{4}\right.$ cells/well) were incubated with rotenone for $24 \mathrm{~h}$ in 96 -well plates. Subsequently, cells were transfected with siRNA EAG1hum_287 (18.75 nM) or the scramble control $(18.75 \mathrm{nM})$ for $24 \mathrm{~h}$. Apoptosis was evaluated using the Caspase-Glo 3/7 assay (Promega Corporation, Madison, WI, United States), according to the manufacturer's protocol. Caspase-Glo substrate $(100 \mu \mathrm{l})$ was added to each well, mixed and incubated at room temperature for $1 \mathrm{~h}$ in the dark. Enzymatic activity was determined by measuring the luminescence with a luminometer $\left(\right.$ GloMax $^{\circledR} 96$ Microplate Luminometer; Promega Corporation). 
A
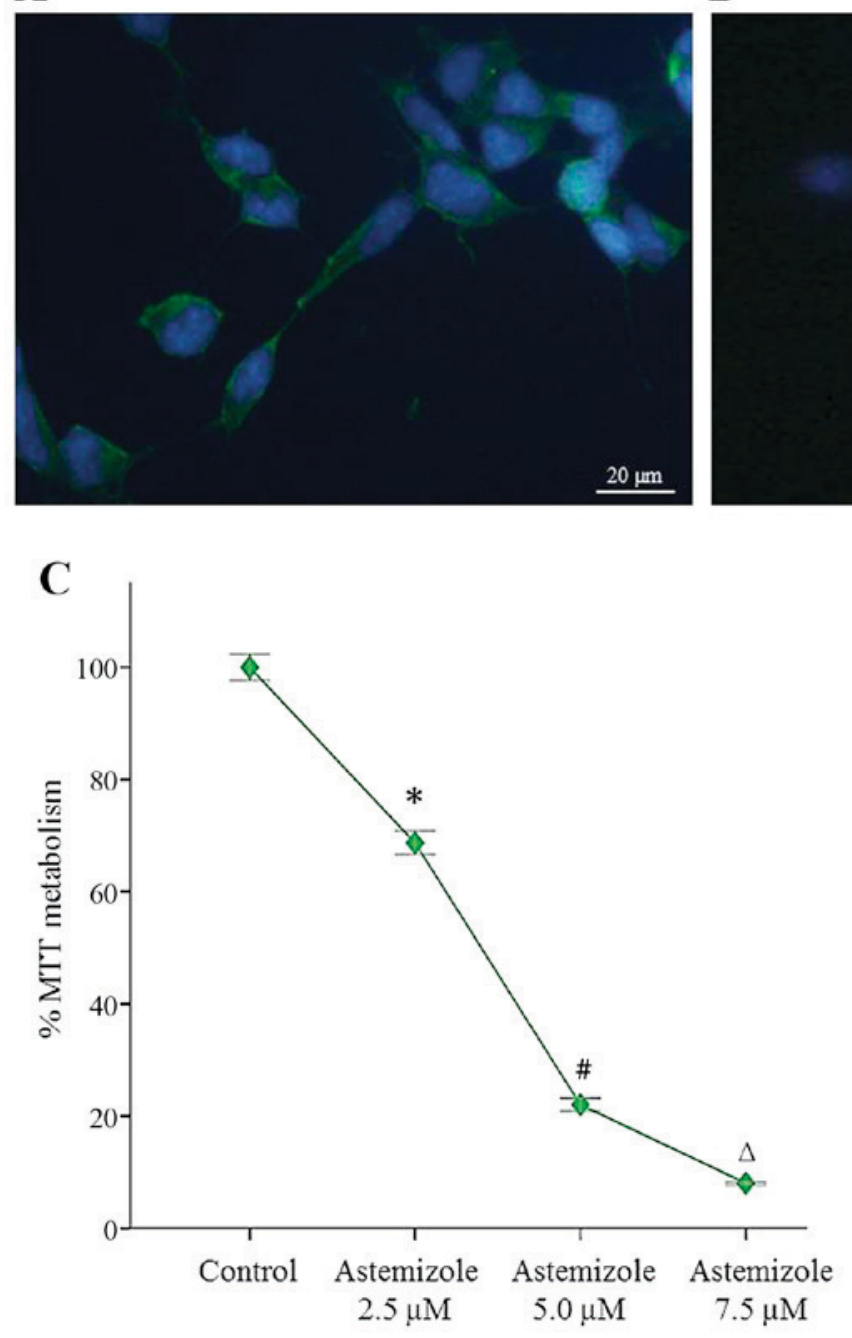

B

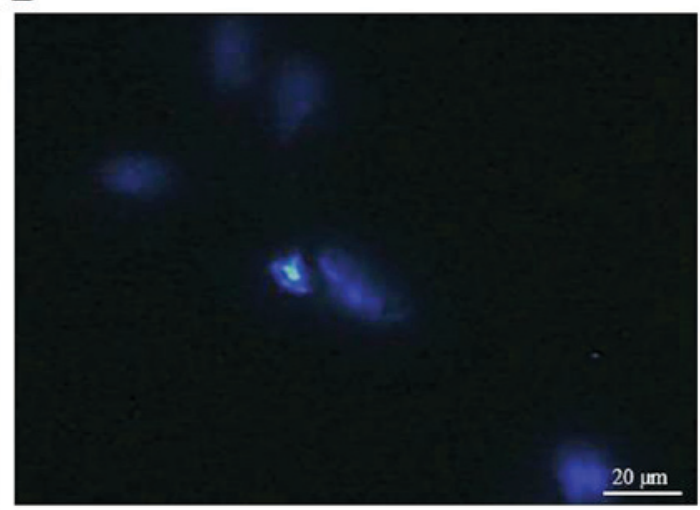

D
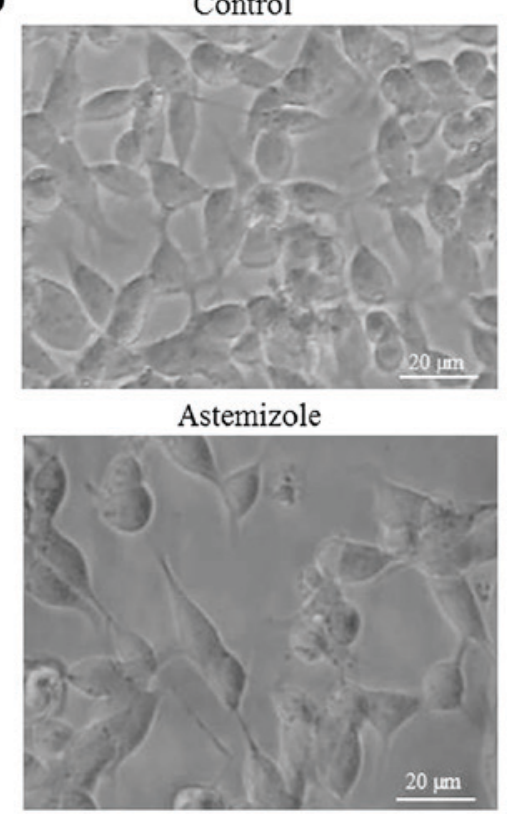

Figure 1. Immunocytochemical detection of Eag1 and the effects of Eag1 suppression on SH-SY5Y cells. (A) Fluorescence microscopy images revealed that SH-SY5Y cells constitutively express Eag1. (B) Negative control SH-SY5Y cell nuclei stained with Hoechst 33342. (C) Effects of astemizole treatment $(2.5,5.0$ and $7.5 \mu \mathrm{M})$ on SH-SY5Y cell viability, as revealed by MTT assay $24 \mathrm{~h}$ following rotenone exposure. (D) Morphological changes and cell confluence were evaluated by light microscopy. ${ }^{*} \mathrm{P}<0.05$ vs. control, astemizole $5.0 \mu \mathrm{M}$ and astemizole $7.5 \mu \mathrm{M}$; ${ }^{\#} \mathrm{P}<0.05$ vs. control and astemizole $2.5 \mu \mathrm{M} ;{ }^{\Delta} \mathrm{P}<0.05$ vs. control and astemizole $2.5 \mu \mathrm{M}$. Eag1, Ether à go-go 1 potassium channel.

Statistical analysis. The statistical package for social sciences (SPSS 17.0; SPSS, Inc., Chicago, IL, USA) was used to analyze the data. Results were presented as the mean \pm standard error of the mean, and the procedures of MTT, RT-qPCR and counting of viable cells were carried out in triplicate. The intergroup differences were tested using one-way analysis of variance followed by Tukey's test. Student t-tests were applied to analyze differences between paired groups. For all comparisons, $\mathrm{P}<0.05$ was considered to indicate a statistically significant difference.

\section{Results}

Expression of Eagl potassium channels and the effect of Eagl inhibition with astemizole on cell viability. Initially, SH-SY5Y cells were confirmed to express Eag1. Using a $\mathrm{mAb} 62$ antibody, Eag1 was revealed to be expressed by these dopaminergic cells, with cell groups incubated with mAb 62 displaying a marked green fluorescence (Fig. 1A).
Conversely, the signal was absent in negative controls lacking the primary antibody (Fig. 1B). The Hoechst reagent was used to stain cell nuclei in both groups. Subsequently, the involvement of Eag1 in SH-SY5Y cell viability was examined in the absence of rotenone-induced damage. Channels were blocked with astemizole and cell viability measured by MTT assay at $24 \mathrm{~h}$. Astemizole treatment $(2.5,5.0$ and $7.5 \mu \mathrm{M})$ resulted in a dose-dependent decrease in cell viability to 68.7 , 22.0 and $8.0 \%$, respectively, compared with the control group $(\mathrm{P}=0.001$; Fig. 1C). Astemizole treatment also visibly reduced cell confluence (Fig. 1D).

Eagl suppression sensitizes SH-SY5Y cells to injury by rotenone. The involvement of Eag1 in rotenone-induced cell damage in dopaminergic cells was subsequently examined. Exposure to $2.5 \mu \mathrm{M}$ rotenone resulted in a visible decrease in SH-SY5Y cell confluence (Fig. 2A), and exposure to 2.5, 10 and $20 \mu \mathrm{M}$ rotenone resulted in a significant dose-dependent decrease in SH-SY5Y cell count (Fig. 2B) and viability 

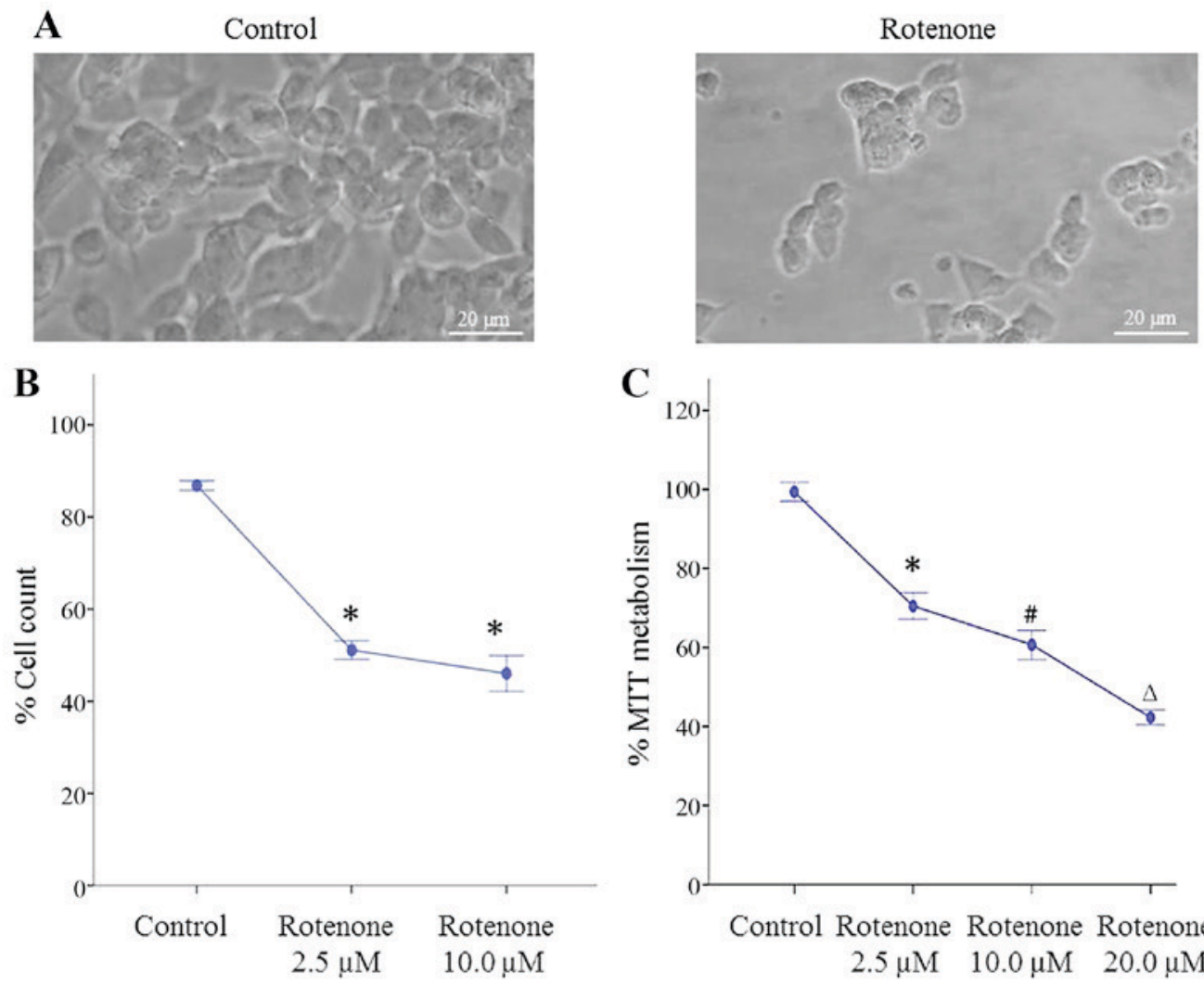

Control Rotenone Rotenone Rotenone $2.5 \mu \mathrm{M} \quad 10.0 \mu \mathrm{M} \quad 20.0 \mu \mathrm{M}$

\section{D}

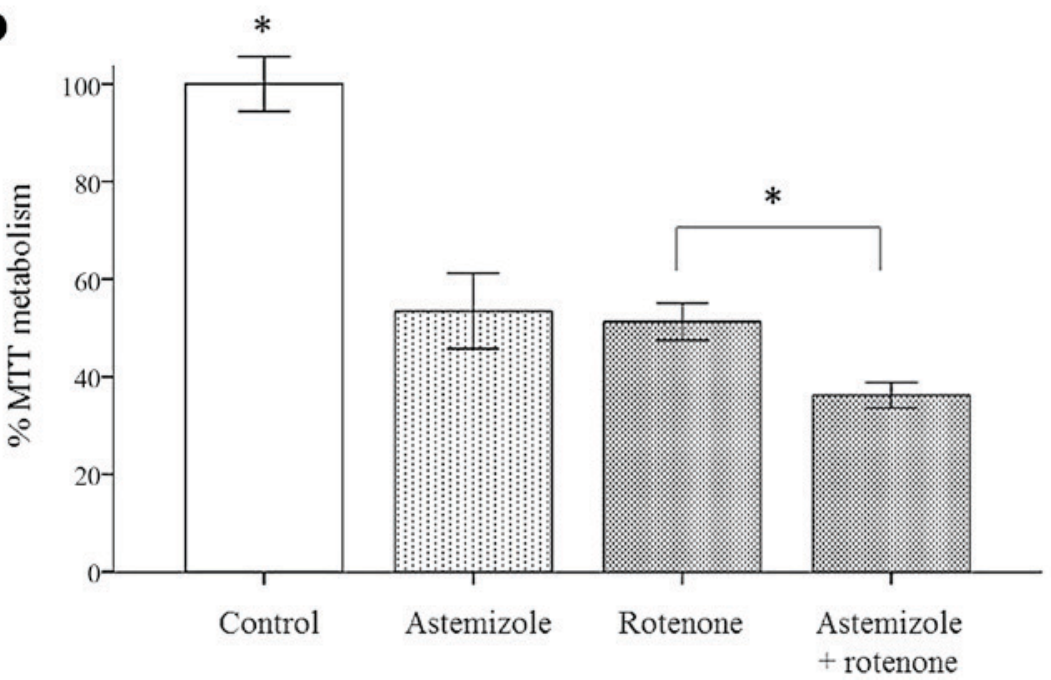

Figure 2. Effects of rotenone exposure and Eag1 inhibition with astemizole on SH-SY5Y cell viability. (A) Morphological changes and confluence, evaluated by light microscopy. (B) Rotenone exposure $(2.5$ and $10.0 \mu \mathrm{M})$ resulted in decreased cell counts, revealed by trypan blue staining. ${ }^{*} \mathrm{P}<0.05$ vs. control. $(\mathrm{C}) \mathrm{MTT}$ assays revealed a dose-dependent decrease in cell viability $24 \mathrm{~h}$ following rotenone injury. ${ }^{*} \mathrm{P}<0.05$, vs. control and rotenone $20.0 \mu \mathrm{M}$; ${ }^{\sharp} \mathrm{P}<0.05$, vs. control; ${ }^{\Delta} \mathrm{P}<0.05$, vs. control and rotenone $2.5 \mu \mathrm{M}$. (D) Effects of Eag1 inhibition with astemizole on cell viability. ${ }^{*} \mathrm{P}<0.05$, vs. astemizole, rotenone and astemizole plus rotenone. Comparisons indicated by lines. Eag1, Ether à go-go 1 potassium channel.

(Fig. 2C). Viability was significantly reduced by $30-60 \%$, following treatment with rotenone $(2.5-20 \mu \mathrm{M})$, as compared with the control group ( $\mathrm{P}=0.001$; Fig. 2C). To address the involvement of the Eag1 potassium channel in cell injury, the Eag1 channels were blocked with astemizole. SH-SY5Y cells treated with astemizole were sensitized to the damage caused by exposure to $2.5 \mu \mathrm{M}$ rotenone, resulting in a $15 \%$ decrease in cell viability compared with cells exposed to rotenone only ( $\mathrm{P}=0.018$; Fig. 2D). These results suggested that Eag1 is involved in dopaminergic cell responses to rotenone-induced injury, and these findings were further explored using RNAi.
Eagl-targeted siRNAs reveal the involvement of Eagl in cell viability and apoptosis in SH-SY5Y cells exposed to rotenone. The effects of Eag1 knockdown on rotenone-induced injury were examined in SH-SY5Y cells. Initially, the ability of targeted siRNAs to silence Eag1 expression was evaluated. A 0.5-fold decrease in Eag1 mRNA content was observed in cells transfected with siRNA EAG1hum_287 compared with normal control ( $\mathrm{P}=0.032$; Fig. 3). However, Eag1 mRNA expression levels, were unchanged in rotenone-exposed SH-SY5Y cells compared with unexposed controls (Fig. 3). Rotenone-exposed and unexposed SH-SY5Y cell viability 


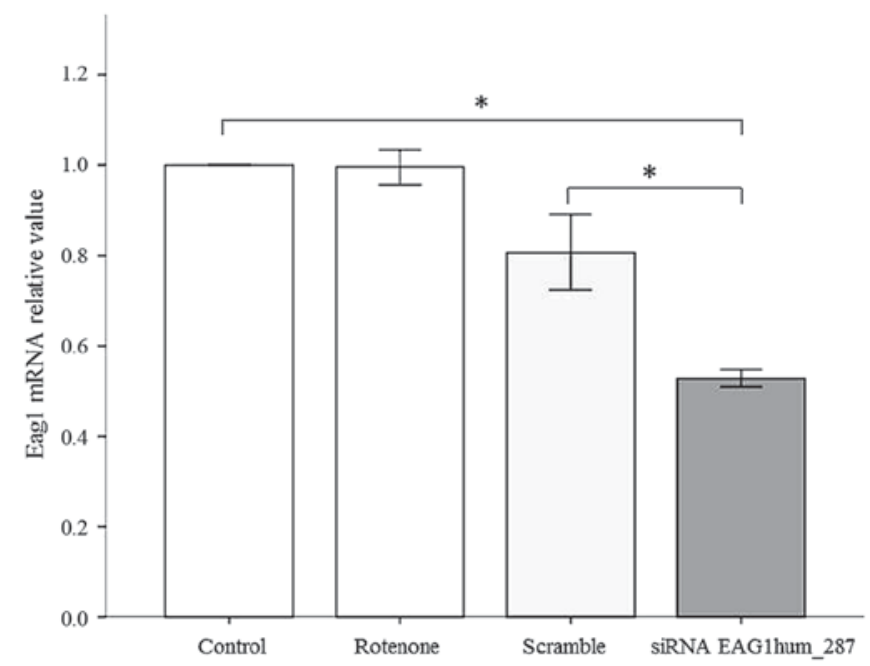

Figure 3. Effects of Eag1 gene silencing in SH-SY5Y cells using siRNA. ${ }^{*} \mathrm{P}<0.05$, comparisons indicated by lines. Eag1, Ether à go-go 1 potassium channel; siRNA, small interfering RNA.

was not affected by transfection with scramble control siRNA (Fig. 4). Conversely, the Eag1-targeted siRNAs (Kv10.1-3 and EAG1hum_287) sensitized cells to rotenone-induced injury, resulting an additional reduction of $16.4 \%(\mathrm{P}=0.036$; Fig. 4) and $23.5 \%$ ( $\mathrm{P}=0.018$; Fig. 4) in cell viability, respectively, compared with untransfected cells exposed to rotenone, and an overall reduction of $42.0 \%(\mathrm{P}<0.05 \mathrm{P}=0.001$; Fig. 4) and 49.1\% ( $\mathrm{P}<0.05 \mathrm{P}=0.001$; Fig. 4), respectively, compared with untreated non-transfected controls. Scrambled siRNAs had no effect on the apoptosis of rotenone-exposed or unexposed SH-SY5Y cells, as revealed by Hoechst 33342 staining (Fig. 5A and B) and caspase 3/7 assays (Fig. 5C). Rotenone exposure increased the number of apoptotic nuclei by $29.7 \%$, compared with control ( $\mathrm{P}=0.001$; Fig. 5B). In addition, silencing of Eag1 caused $11 \%$ induction of the rate of apoptosis in comparison with scramble ( $\mathrm{P}=0.013$; Fig. 5B). Furthermore, Eag1 silencing increased the rate of rotenone-induced apoptosis by $33 \%$ compared with control group as revealed by Hoechst assay $(\mathrm{P}=0.025$; Fig. 5B). Caspase $3 / 7$ activity was also increased in rotenone-exposed cells compared with unexposed control cells $(\mathrm{P}=0.001$; Fig. 5C). This rotenone-induced increase in caspase $3 / 7$ activity was potentiated by transfection with Eag1-targeted siRNA EAG1hum_287 compared with cells exposed to rotenone only (3.9- vs. 5.8-fold; $\mathrm{P}=0.011$; Fig. 5C).

Relative expression of $\mathrm{miR}$-34 a following rotenone exposure and downregulation with a specific antagonist antimiR; effects of miR-34a inhibition on rotenone-injured cells. Rotenone-induced damage to SH-SY5Y cells was revealed to be increased in Eag1-silenced groups. Therefore, it was hypothesized that a miRNA previously described as an Eag1 regulator (miR-34a) (9) would be increased in rotenone-exposed cells. Rotenone exposure resulted in a 2.7-fold increase in miR-34a content, as revealed by RT-qPCR analysis (Fig. 6A). The antisense oligonucleotide to miR-34a counteracted the rotenone-induced increase in miR-34a $(\mathrm{P}=0.041$; Fig. 6A). The marked increase of miR-34a in rotenone-exposed cells suggests that it is involved in cell injury. To address this,
miR-34a was inhibited in cells exposed to rotenone and the effect on cell viability was examined. Inhibition of miR-34a resulted in a significant improvement in the viability of cells exposed to rotenone for $2 \mathrm{~h}(8.4 \% ; \mathrm{P}=0.031$; Fig. $6 \mathrm{~B})$ or $24 \mathrm{~h}$ (8.9\%; $\mathrm{P}=0.044$; Fig. 6C). Beyond indicating the involvement of miR-34a in rotenone-induced injury, the results of the present study also highlight a potential novel strategy to protect dopaminergic cells based on the suppression of miR-34a.

\section{Discussion}

The loss of dopaminergic neurons in the substantia nigra pars compacta is a characteristic neuropathological alteration associated with Parkinson's disease (25). A previous study using the 6-OHDA model of Parkinson's disease revealed that dopaminergic cells in the nigrostriatal pathway express Eag1 (11). 6-OHDA-injured animals presented a decrease in Eag1-positive cells proportional to the dopaminergic neuronal loss in the nigrostriatal pathway. The present study also addressed the involvement of Eag1 in neuronal death. An in vitro model of dopaminergic neurons, the SH-SY5Y cell line, was used. This model mimics several features of dopaminergic neurons and the pathological changes that occur during neuronal death $(8,26)$. Initially, SH-SY5Y cells were revealed to express Eag1, corroborating the findings of a previous study (27). In addition, Eag1 was required to preserve SH-SY5Y cell viability. Suppression of Eag1 channels by astemizole resulted in a dose-dependent decrease in SH-SY5Y cell viability, suggesting their involvement in neuronal cell biology. Potassium channels in the basal ganglia have previously been demonstrated to regulate neuronal excitability and neurotransmitter release $(28,29)$.

Potassium channels are also involved in the pathophysiology of various diseases $(30,31)$. Changes in potassium channel expression in the basal ganglia contribute to neurodegeneration. The potassium channel Kir2.3 has been demonstrated to protect against rotenone-induced programmed cell death in the PC12 cell line (30). In the present study, the potassium channel Eag1 was examined to determine whether it had the same function in rotenone-induced injury of dopaminergic SH-SY5Y cells. The results of the present study revealed that Eag1 suppression with astemizole intensified rotenone-induced injury, suggesting this channel may serve a neuroprotective function in SH-SY5Y cells, as Kir2.3 does in PC12 cells. Silencing Eag1 with specific siRNAs (EAG1hum_287 or Kv10.1-3) also increased the severity of rotenone-induced injury, reinforcing the notion that this potassium channel is involved in the dopaminergic cell response against chemical injury. Furthermore, an increased rate of apoptosis was observed in Eag1-silenced cells.

The data generated by MTT assays in studies relating to rotenone may share an intrinsic limitation. MTT measures the level of NADH in the cell, and rotenone directly affects $\mathrm{NADH}$ levels by acting in the mitochondria. In the present study, a different method regarding cell injury was also used: The counting of viable cells by trypan blue staining. Rotenone exposure resulted in a reduced cell count that was similar to the decrease in cell viability measured by MTT assay. In addition, previous work has revealed that cells generate $\mathrm{NADH}$ in regions other than the mitochondria, 


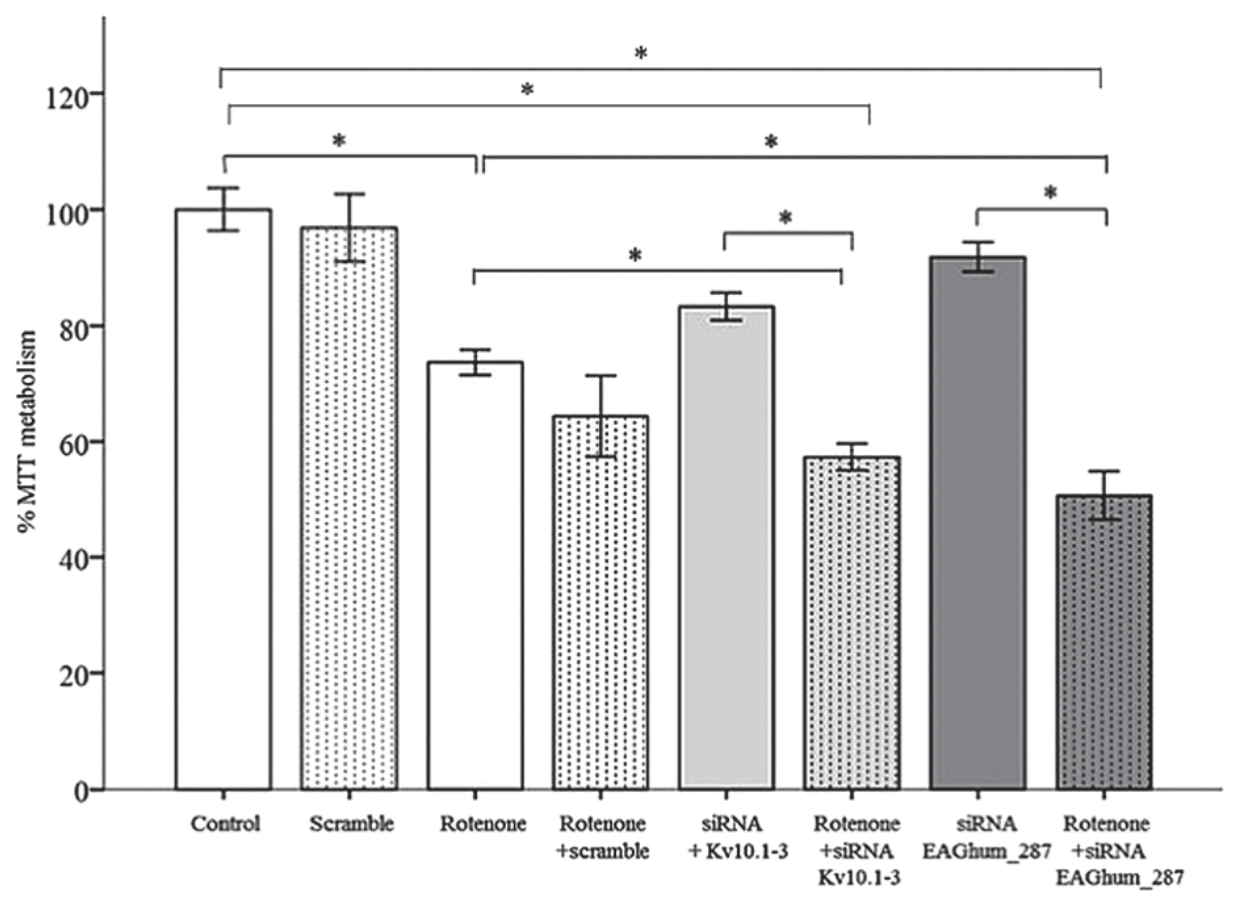

Figure 4. Transfection of SH-SY5Y cells with siRNAs to silence Eag1 potentiates the reduction in cell viability caused by exposure to rotenone. MTT assays were performed $48 \mathrm{~h}$ following exposure to rotenone. ${ }^{*} \mathrm{P}<0.05$, comparisons indicated by lines. Eag1, Ether à go-go 1 potassium channel; siRNA, small interfering RNA.

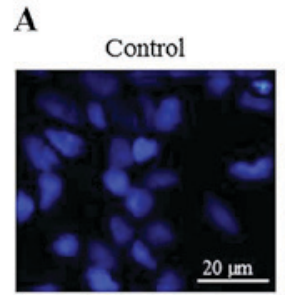

B
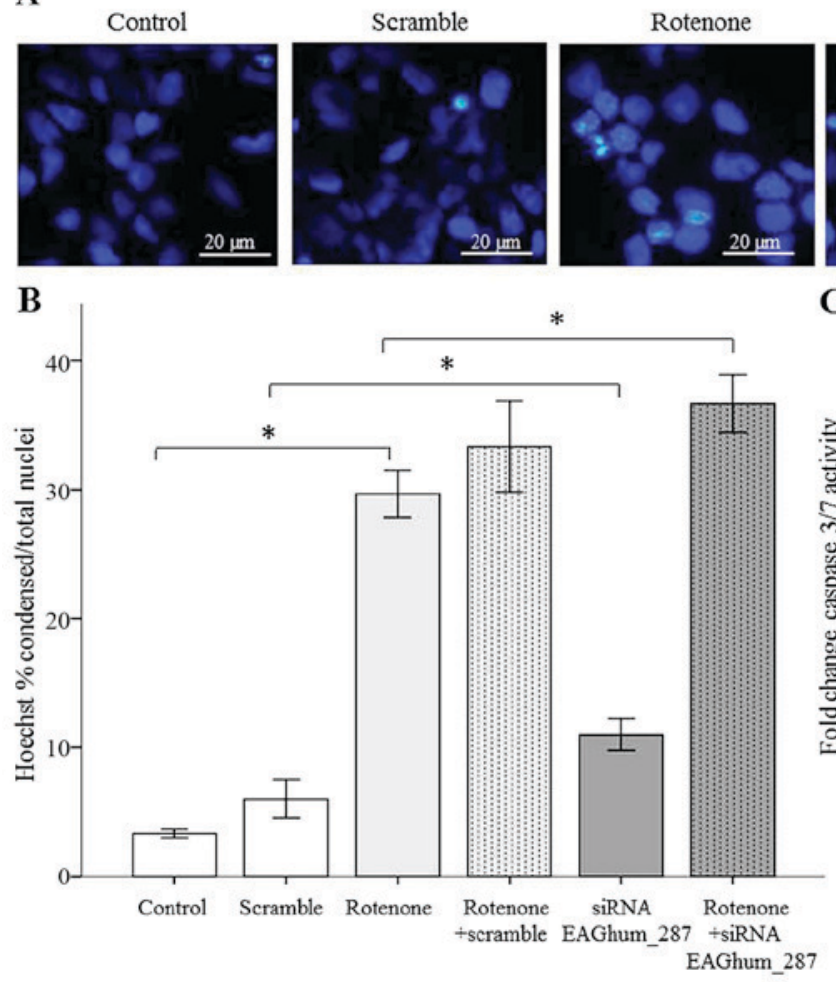

SiRNA

Rotenone+scramble

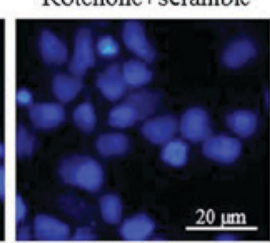

EAGlhum_287

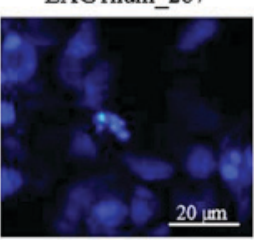

+ siRNA EAG1hum_287

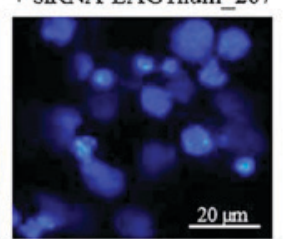

C

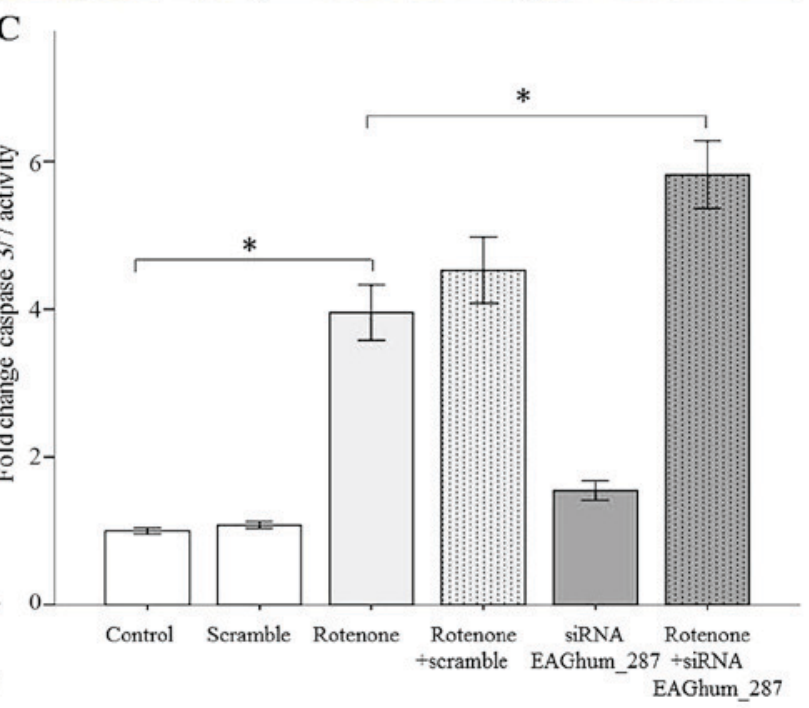

Figure 5. Silencing of Eag1 in SH-SY5Y cells potentiates rotenone-induced apoptosis. (A) Apoptotic nuclei in SH-SY5Y cells exposed to rotenone and transfected with siRNA EAG1hum_287, stained by Hoechst 33342 (B) Quantification of Hoechst 33342 staining. (C) Cellular activity of caspase 3 and 7 is increased in SH-SY5Y cells injured by rotenone which is potentiated by Eag1-targeted siRNA EAG1hum_287. Caspases 3/7 activity was unchanged in cells transfected with scramble siRNAs. ${ }^{*} \mathrm{P}<0.05$, comparisons indicated by lines. Eag1, Ether à go-go 1 potassium channel; siRNA, small interfering RNA.

where rotenone acts (32). The data from the present study suggested that the MTT assay still produces valuable information in studies with rotenone. This method provided concordant results with cell counting using trypan blue 

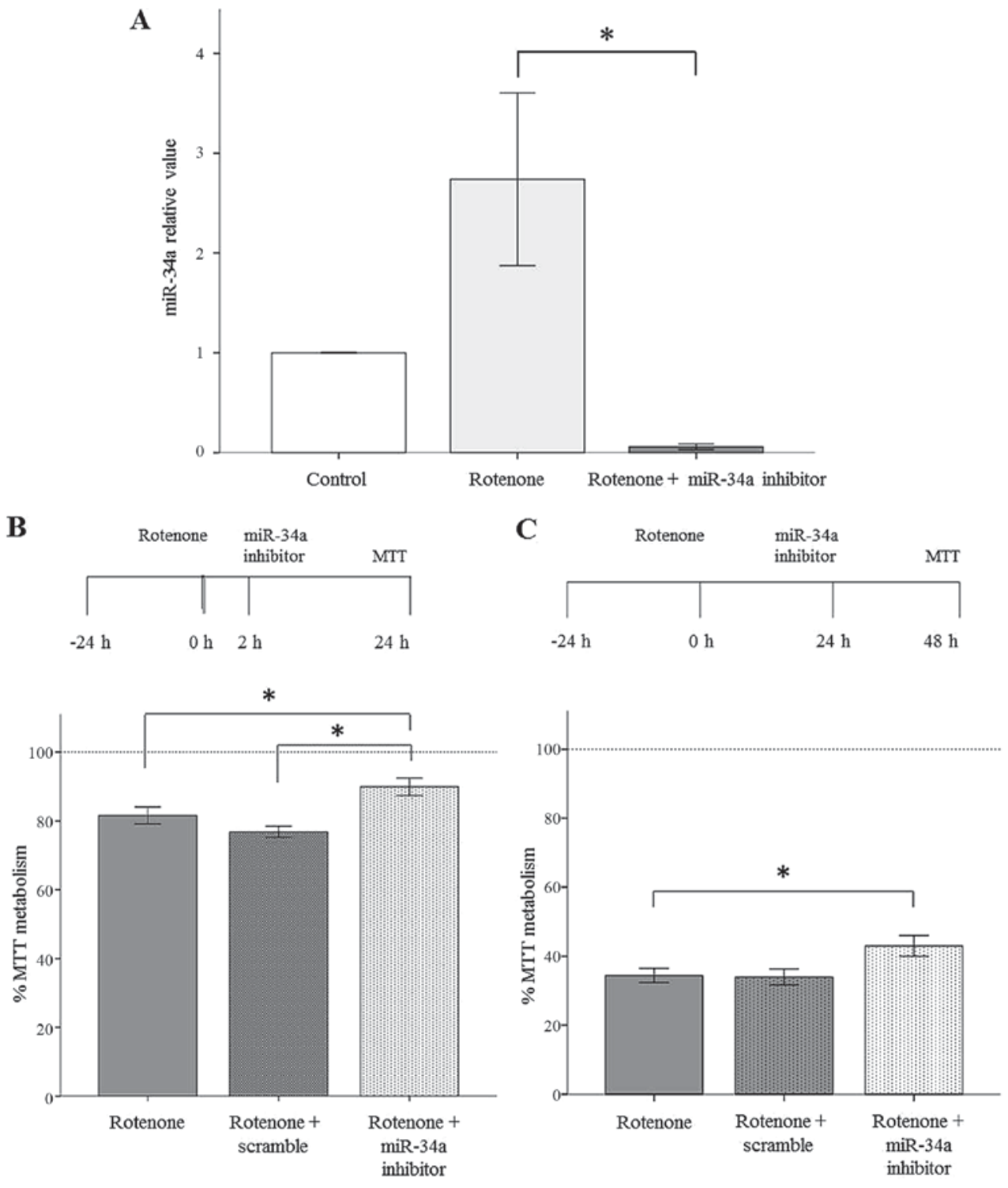

Figure 6. mir-34a inhibition downregulates miR-34a and protects dopaminergic cells against rotenone-induced injury. (A) Effects of rotenone exposure and treatment with an miR-34a inhibitor on miR-34a expression in SH-SY5Y cells. Effects of treatment with an miR-34a inhibitor on the viability of rotenone-exposed cells (B) 2 and (C) $24 \mathrm{~h}$ following rotenone exposure. A schematic representation of the experimental procedure is displayed at the top of $(\mathrm{B}$ and $\mathrm{C}) .{ }^{*} \mathrm{P}<0.05$, comparisons indicated by lines. mir-34a, microRNA-34a.

staining and, also, with methodologies that evaluated the rate of cell apoptosis.

There is growing evidence to support the importance of miRNAs in the development and physiology of the nervous system (33). Conversely, dysregulated miRNA networks may result in pathological alterations observed in brain diseases $(34,35)$. As one unique miRNA regulates numerous target genes, aberrant miRNA expression assumes an increased importance $(36,37)$. In mammals, the miR-34 family includes three homologous transcripts $(\mathrm{miR}-34 \mathrm{a} / \mathrm{b} / \mathrm{c})$ that have their expression regulated by $\mathrm{p} 53$ proteins (38). miR-34a expression is highest in the brain (39). Eag1 and miR-34a have critical functions in injured cells that are still under investigation. The Eag1 channel is constitutively expressed in healthy cells, including neurons, and is involved in $\mathrm{K}^{+}$flux across the plasma membrane (12). Furthermore, cancer cells overexpress Eag1, which contributes to cell growth and tumor expansion (14).
The molecular mechanisms that control Eag1 expression at transcriptional and post-transcriptional levels are a complex matter worthy of further studies. Two common outcomes have previously been demonstrated, regardless of the cell model used. Firstly, an injury may affect cell viability without causing a significant change in Eag1 content. In response to damage caused by an antineoplastic drug (temozolomide), glioma cell viability was reduced by $\sim 50 \%$, which resulted in a mild, insignificant decrease in Eag1 expression (40). A similar result was observed in the present study, since rotenone exposure resulted in no significant changes in Eag1 expression. Secondly, and more importantly, in these experimental conditions Eag1 is associated with cell viability during injury. In these models (SH-SY5Y/rotenone and glioma/temozolomide), suppression of Eag1, either by pharmacological inhibition with astemizole or by gene silencing with siRNAs, increased the severity of drug-induced injury. Therefore, cells with reduced Eag1 levels 
may have a reduced capacity to ameliorate chemical damage, which results in their eventual apoptosis. However, an opposite outcome was observed with miR-34a. miR-34a levels were increased following rotenone-induced injury, and miR-34a suppression protected cells against this injury. The inverse relationship between miR-34a and Eag1, in a pathway that involves p53 and E2F1 (p53-miR-34-E2F1-Eag1) was previously studied in SH-SY5Y cells (9). The authors induced cell growth arrest by p53 activation with nutlin-3. Overexpression of E2F1 or inhibition with miR-34a prevented p53-induced apoptosis. Eag1 silencing by antisense oligonucleotides reduced the growth-stimulation effect of E2F1 and, in addition, abrogated the effects of p53 inactivation. This study revealed a molecular pathway that regulated Eag1 content, in a model of apoptosis triggered by nutlin-3, a p53 activator that is not a toxin. The present study used the neurotoxin rotenone, which damages dopaminergic cells and results in complex changes to cell metabolism. Changes induced by rotenone may involve other signaling molecules that maintain stable Eag1 expression, even with an increased miR-34a expression. Despite the differences in apoptosis models, both studies revealed that miR-34a and Eag1 appear to serve opposite functions regarding cell viability and apoptosis.

In a recent study, lithium was demonstrated to protect SH-SY5Y cells from paraquat injury, and this neuroprotection was dependent on miR-34a downregulation (41). miR-34a inhibitors also demonstrated a neuroprotective effect on hippocampal cells, preserving these cells from injury caused by lithium-pilocarpine and kainic acid $(20,21)$. The use of miRNA inhibitors to protect brain areas from injury has also been reported in studies on animal models, with miR-134 inhibitors reducing hippocampal damage and seizures triggered by kainic acid or pilocarpine $(42,43)$. Taken together, these studies reveal the potential of miRNA inhibitors to change the pathological course of neurodegenerative diseases. The results of the present study suggested that miR-34a may be a promising novel target for a miRNA-based therapy aimed to prevent dopaminergic neuronal death.

In conclusion, these data supported the involvement of Eag1 potassium channels in rotenone-exposed SH-SY5Y cell viability. The miR-34a inhibitor described in the present study merits further study in a rotenone rodent model, to evaluate its ability to protect nigrostriatal neurons and revert motor signs of parkinsonism in vivo.

\section{Acknowledgements}

The present study received financial support from the following Brazilian institution: Coordenação de Aperfeiçoamento de Pessoal de Nível Superior (Programa Nacional de Pós-doutorado; grant no. 3731-37/2010).

\section{References}

1. Shulman JM, De Jager PL and Feany MB: Parkinson's disease: Genetics and pathogenesis. Annu Rev Pathol 6: 193-222, 2011.

2. Tanner CM, Kamel F, Ross GW, Hoppin JA, Goldman SM, Korell M, Marras C, Bhudhikanok GS, Kasten M, Chade AR, et al: Rotenone, paraquat, and Parkinson's disease. Environ Health Perspect 119: 866-872, 2011.

3. Bové J, Prou D, Perier C and Przedborski S: Toxin-induced models of Parkinson's disease. NeuroRx 2: 484-494, 2005.
4. Betarbet R, Sherer TB, MacKenzie G, Garcia-Osuna M, Panov AV and Greenamyre JT: Chronic systemic pesticide exposure reproduces features of Parkinson's disease. Nat Neurosci 3: 1301-1306, 2000

5. Dauer W and Przedborski S: Parkinson's disease: Review. mechanisms and models. Neuron 39: 889-909, 2003.

6. Uversky VN: Neurotoxicant-induced animal models of Parkinson's disease: Understanding the role of rotenone, maneb and paraquat in neurodegeneration. Cell Tissue Res 318: 225-241, 2004.

7. Przedborski S: Pathogenesis of nigral cell death in Parkinson's disease. Parkinsonism Relat Disord 11 (Suppl 1): S3-S7, 2005.

8. Xie HR, Hu LS and Li GY: SH-SY5Y human neuroblastoma cell line: In vitro cell model of dopaminergic neurons in Parkinson's desease. Chin Med J (Engl) 123: 1086-1092, 2010.

9. Lin H, Li Z, Chen C, Luo X, Xiao J, Dong D, Lu Y, Yang B and Wang Z: Transcriptional and post-transcriptional mechanisms for oncogenic overexpression of ether à go-go $\mathrm{K}+$ channel. PLoS One 6: e20362, 2011.

10. Bernstein AI, Garrison SP, Zambetti GP and O'Malley KL: 6-OHDA generated ROS induces DNA damage and p53- and PUMA-dependent cell death. Mol Neurodegener 6: 2, 2011.

11. Ferreira NR, Mitkovski M, Stühmer W, Pardo LA and Del Bel EA: Ether-à-go-go 1 (Eag1) potassium channel expression in dopaminergic neurons of the basal ganglia is modulated by 6-hydroxydopamine lesion. Neurotox Res 21: 317-333, 2012.

12. Brüggemann A, Pardo LA, Stühmer W and Pongs O: Ether-a-go-go encodes a voltage-gated channel permeable to $\mathrm{K}+$ and $\mathrm{Ca} 2+$ and modulated by cAMP. Nature 365: 445-448, 1993.

13. Kondratskyi A, Kondratska K, Skryma R and Prevarskaya N: Ion channels in the regulation of apoptosis. Biochim Biophys Acta 1848: 2532-2546, 2015.

14. Urrego D, Tomczak AP, Zahed F, Stühmer W and Pardo LA: Potassium channels in cell cycle and cell proliferation. Philos Trans R Soc Lond B Biol Sci 369: 20130094, 2014.

15. Manfredsson FP, Lewin AS and Mandel RJ: RNA knockdown as a potential therapeutic strategy in Parkinson's disease. Gene Ther 13: 517-24, 2006.

16. Weber C, Mello de Queiroz F, Downie BR, Suckow A, Stühmer W and Pardo LA: Silencing the activity and proliferative properties of the human Eag1 potassium channel by RNA interference. J Biol Chem 281: 13030-13037, 2006.

17. Cunha LC, Del Bel E, Pardo L, Stühmer W and Titze-de-Almeida R: RNA interference with EAG1 enhances interferon gamma injury to glioma cells in vitro. Anticancer Res 33: 865-870, 2013.

18. Junn E and Mouradian MM: MicroRNAs in neurodegenerative diseases and their therapeutic potential. Pharmacol Ther 133: $142-50,2012$

19. Heman-Ackah SM, Hallegger M, Rao MS and Wood MJ: RISC in PD: The impact of microRNAs in Parkinson's disease cellular and molecular pathogenesis. Front Mol Neurosci 20: 40, 2013.

20. Hu K, Xie YY, Zhang C, Ouyang DS, Long HY, Sun DN, Long LL, Feng L, Li Y and Xiao B: MicroRNA expression profile of the hippocampus in a rat model of temporal lobe epilepsy and miR-34a-targeted neuroprotection against hippocampal neurone cell apoptosis post-status epilepticus. BMC Neurosci 13: 115, 2012.

21. Sano T, Reynolds JP, Jimenez-Mateos EM, Matsushima S, Taki W and Henshall DC: MicroRNA-34a upregulation during seizure-induced neuronal death. Cell Death Dis 3: e287, 2012.

22. Kwon MJ, Oh E, Lee S, Roh MR, Kim SE, Lee Y, Choi YL, In YH, Park T, Koh SS and Shin YK: Identification of novel reference genes using multiplatform expression data and their validation for quantitative gene expression analysis. PLoS One 4: e6162, 2009.

23. Livak KJ and Schmittgen TD: Analysis of relative gene expression data using real-time quantitative PCR and the 2(-Delta Delta C(T)) method. Methods 25: 402-408, 2001.

24. Ririe KM, Rasmussen RP and Wittwer CT: Product differentiation by analysis of DNA melting curves during the polymerase chain reaction. Anal Biochem 245: 154-460, 1997.

25. Agid Y: Parkinson's disease: Pathophysiology. Lancet 337: 1321-1324, 1991.

26. Alberio T, Lopiano L and Fasano M: Cellular models to investigate biochemical pathways in Parkinson's disease. FEBS J 297: $1146-1155,2012$.

27. Meyer R and Heinemann SH: Characterization of an eag-like potassium channel in human neuroblastoma cells. J Physiol 508: 49-56, 1998. 
28. Kazmierczak M, Zhang X, Chen B, Mulkey DK, Shi Y, Wagner PG, Pivaroff-Ward K, Sassic JK, Bayliss DA and Jegla T: External pH modulates EAG superfamily $\mathrm{K}+$ channels through EAG-specific acidic residues in the voltage sensor. J Gen Physiol 141: 721-735, 2013.

29. Wang Y, Yang PL, Tang JF, Lin JF, Cai XH, Wang XT and Zheng GQ: Potassium channels: Possible new therapeutic targets in Parkinson's disease. Med Hypotheses 71: 546-550, 2008.

30. Sanguinetti MC and Spector PS: Potassium channelopathies. Neuropharmacology 36: 755-762, 1997.

31. Shieh CC, Coghlan M, Sullivan JP and Gopalakrishnan M: Potassium channels: Molecular defects, diseases, and therapeutic opportunities. Pharmacol Rev 52: 557-594, 2000.

32. Berridge MV, Tan AS, McCoy KD and Wang R: The biochemical and cellular basis of cell proliferation assays that use tetrazolium salts. Biochemica 4: 14-19, 1996.

33. Kosik KS: The neuronal microRNA system. Nat Rev Neurosci 7: 911-920, 2006.

34. Hébert SS and De Strooper B: Alterations of the microRNA network cause neurodegenerative disease. Trends Neurosci 32 199-206, 2009.

35. Weinberg MS and Wood MJ: Short non-coding RNA biology and neurodegenerative disorders: Novel disease targets and therapeutics. Hum Mol Genet 18: R27-R39, 2009.

36. Baek D, Villén J, Shin C, Camargo FD, Gygi SP and Bartel DP: The impact of microRNAs on protein output. Nature 455: 64-71, 2008.

37. Selbach M, Schwanhäusser B, Thierfelder N, Fang Z, Khanin R and Rajewsky N: Widespread changes in protein synthesis induced by microRNAs. Nature 455: 58-63, 2008
38. Seeliger MA and Moll UM: p73-constitutively open for business. Cell Death Differ 20: 972-973, 2013.

39. Olsen L, Klausen M, Helboe L, Nielsen FC and Werge T: MicroRNAs show mutually exclusive expression patterns in the brain of adult male rats. PLoS One 4: e7225, 2009.

40. Sales TT, Resende FF, Chaves NL, Titze-de-Almeida SS, Báo SN, Brettas ML and Titze-de-almeida R: Suppression of the Eag1 potassium channel sensitizes glioblastoma cells to injury caused by temozolomide. Oncol Lett 12: 2581-2589, 2016.

41. Alural B, Ozerdem A, Allmer J, Genc K and Genc S: Lithium protects against paraquat neurotoxicity by NRF2 activation and miR-34a inhibition in SH-SY5Y cells. Front Cell Neurosci 9: 209, 2015.

42. Jimenez-Mateos EM, Engel T, Merino-Serrais P, McKiernan RC, Tanaka K, Mouri G, Sano T, O'Tuathaigh C, Waddington JL, Prenter S, et al: Silencing microRNA-134 produces neuroprotective and prolonged seizure-suppressive effects. Nat Med 18 1087-1094, 2012

43. Jimenez-Mateos EM, Engel $T$, Merino-Serrais $P$, Fernaud-Espinosa I, Rodriguez-Alvarez N, Reynolds J, Reschke CR, Conroy RM, McKiernan RC, deFelipe J and Henshall DC: Antagomirs targeting microRNA-134 increase hippocampal pyramidal neuron spine volume in vivo and protect against pilocarpine-induced status epilepticus. Brain Struct Funct 220: 2387-2399, 2015. 